\title{
Cardiac transplantation can be safely performed using selected diabetic donors
}

\author{
Sharven Taghavi, MD, MPH, ${ }^{a}$ Senthil N. Jayarajan, MD, ${ }^{a}$ Lynn M. Wilson, RN, ${ }^{b}$ Eugene Komaroff, PhD, ${ }^{c}$ \\ Jeffrey M. Testani, MD, MTR, ${ }^{\mathrm{d}}$ and Abeel A. Mangi, MD $^{\mathrm{b}}$
}

\begin{abstract}
Objective: Cardiac transplantation (OHT) using diabetic donors (DDs) is thought to adversely influence survival. We attempt to determine if adult OHT can be safely performed using selected DDs.
\end{abstract}

\begin{abstract}
Methods: The United Network for Organ Sharing (UNOS) database was examined for adult OHT from 2000 to 2010.

Results: Of the 20,348 patients undergoing OHT, 496 (2.4\%) were with DDs. DDs were older (39.6 vs 31.3 years; $P<.001)$, more likely female $(41.5 \%$ vs $28.3 \% ; P<.001)$, and had a higher body mass index (BMI) (29.9 vs $26.4 ; P<.001)$. Recipients of DD hearts were older $(53.4$ vs $51.8 ; P=.004$ ) and more likely to have diabetes $(18.9 \%$ vs $14.9 \% ; P=.024)$. The 2 groups were evenly matched with regard to recipient male gender $(78.0 \%$ vs $76.1 \% ; P=.312)$, ischemic time (3.3 vs 3.2 hours; $P=.191)$, human leukocyte antigen mismatches (4.7 vs $4.6 ; P=.483$ ), and requirement of extracorporeal membrane oxygenation (ECMO) as a bridge to transplant $(0.8 \%$ vs $0.5 \% ; P=.382)$. Median survival was similar ( 3799 vs 3798 days; $P=.172)$. On multivariate analysis, DD was not associated with mortality (hazard ratio [HR], 1.155; 95\% confidence interval [CI], $0.943-1.415 ; P=.164)$. As previously demonstrated, donor age, decreasing donor BMI, ischemic time, recipient creatinine, recipient black race, recipient diabetes, race mismatch, and mechanical ventilation or ECMO as a bridge to transplant were associated with mortality. On multivariate analysis of subgroups, neither insulindependent diabetes $(1.173 ; 95 \% \mathrm{CI}, 0.884-1.444 ; P=.268)$ nor duration of diabetes for more than 5 years (HR, 1.239; 95\% CI, 0.914-1.016; $P=.167$ ) was associated with mortality.
\end{abstract}

Conclusions: OHT can be safely performed using selected DDs. Consensus criteria for acceptable cardiac donors can likely be revised to include selected DDs. (J Thorac Cardiovasc Surg 2013;146:442-7)

Cardiac transplantation remains the accepted treatment of choice for end-stage heart failure. ${ }^{1}$ However, increasing wait list mortality and donor shortages obligate us to investigate means by which the number of available donors might be expanded. Numerous attempts to increase the donor pool have been made, and this has led to the use of donor hearts once thought to be unsuitable for transplantation. ${ }^{2-8}$ Multiple donor and recipient characteristics have been shown to influence survival in cardiac transplantation. ${ }^{9-13}$ Existing data on the use of hearts of diabetic donors, which otherwise fulfill standard criteria for donation, have been conflicting. ${ }^{8,14}$ In this study, we attempt to determine

From Department of Surgery, ${ }^{\text {a }}$ Temple University Hospital, Philadelphia, Pa; Division of Cardiac Surgery, ${ }^{b}$ Yale University School of Medicine, New Haven, Conn; Department of Public Health, ${ }^{\mathrm{c}}$ Temple University, Philadelphia, Pa; and Department of Internal Medicine and Program of Applied Translational Research, ${ }^{\mathrm{d}}$ Yale University School of Medicine, New Haven, Conn.

Disclosures: Authors have nothing to disclose with regard to commercial support.

Presented at the 8th Annual Academic Surgical Congress, February 5-7, 2013, New Orleans, La.

Received for publication Dec 9, 2012; revisions received Jan 19, 2013; accepted for publication Feb 14, 2013; available ahead of print March 13, 2013.

Address for reprints: Abeel A. Mangi, MD, Section of Cardiac Surgery, Yale University School of Medicine, Boardman 204, 330 Cedar St, New Haven, CT 06510 (E-mail: abeel.mangi@gmail.com).

$0022-5223 / \$ 36.00$

Copyright (c) 2013 by The American Association for Thoracic Surgery

http://dx.doi.org/10.1016/j.jtcvs.2013.02.047 whether adult cardiac transplantation can be safely performed using diabetic donors who otherwise fulfill standard criteria for organ donation according to the United Network for Organ Sharing (UNOS) database. We examined donor insulin dependence and duration of diabetes to determine whether these factors affected recipient survival. We hypothesized that cardiac transplantation could be safely performed using diabetic donors.

\section{METHODS \\ Data Source}

After approval from our local institutional review board, public-use data files were obtained from the UNOS registry. There were 20,348 primary, adult heart transplants performed in the United States from January 2000 to December 2010 in recipients aged 18 years or older as reported to UNOS. Of these, 496 (2.4\%) patients received a donor heart from a diabetic donor. This cohort of patients was compared with patients receiving a heart from nondiabetic donors. The primary end point measured was riskadjusted all-cause mortality. Secondary end points include acute rejection episodes before discharge and total hospital length of stay. The presence of donor diabetes in the UNOS database was based on medical history.

\section{Statistical Analysis}

Student $t$ test and $\chi^{2}$ test were used to examine continuous and categorical variables. Continuous variables are presented as mean \pm standard deviation and categorical variables are reported as percentages of the total number of data points available for that field. Survival curves were 


$$
\begin{aligned}
& \text { Abbreviations and Acronyms } \\
& \begin{aligned}
\text { BMI } & =\text { body mass index } \\
\text { CI } & =\text { confidence interval } \\
\text { ECMO } & =\text { extracorporeal membrane oxygenation } \\
\text { HR } & =\text { hazard ratio } \\
\text { UNOS } & =\text { United Network for Organ Sharing }
\end{aligned}
\end{aligned}
$$

generated by the Kaplan-Meier method and compared with the long-rank test. Cox proportional regression analysis was performed in 2 steps. First, covariates were run in a univariate analysis as predictors of mortality. Next, covariates with a $P$ value $<.20$ were entered simultaneously in the Cox model. In addition, we tested 2-way interactions between donor diabetes and recipient age, recipient gender, donor age, donor gender, ischemic time, and recipient history of diabetes. Because none of these interactions was significant, they were not retained in the final model. Covariates missing greater than $15 \%$ of data in the registry were excluded from the analysis. Survival was determined using all-cause mortality.

\section{RESULTS}

\section{Recipient Characteristics}

Recipient characteristics are shown in Table 1. Recipients of hearts from diabetic donors were older (51.8 vs 53.4 years; $P=.004$ ), more likely to have diabetes themselves $(14.9 \%$ vs $18.9 \% ; P=.024)$, were more likely to receive hearts from opposite sex donors $(27.7 \%$ vs $32.9 \%$; $P=.011$ ), and more likely to require mechanical ventilation while awaiting transplantation $(2.8 \%$ vs $4.8 \% ; P=.007)$. The 2 groups were evenly matched with regard to gender, ethnicity, body mass index (BMI), ischemic time, cardiac output, pulmonary vascular resistance, race mismatch, number of total human leukocyte antigen mismatches, pretransplant serum creatinine, and requirement of extracorporeal membrane oxygenation (ECMO) as a bridge to transplantation.

\section{Donor Characteristics}

Donor characteristics are shown in Table 2. Donors with diabetes were older ( 31.3 vs 39.6 years; $P<.001$ ), less likely to be male $(71.7$ vs $58.5 ; P<.001)$, and had higher BMI (26.4 vs $\left.29.9 \mathrm{~kg} / \mathrm{m}^{2} ; P=.001\right)$. Diabetic donors were also more likely to be evaluated with coronary angiography $(20.5 \%$ vs $48.2 \% ; P<.001)$ and less likely to be evaluated by echocardiography $(97.5 \%$ vs $94.2 \% ; P<.001)$. The 2 donor groups were evenly matched with regard to ejection fraction, creatinine clearance, requirement of inotropic support or vasodilators at procurement, requirement of antihypertensive agents at crossclamp, and medical history of myocardial infarction. Diabetic donors were more likely to be heavy smokers ( $>20$ pack-year history) $(24.5 \%$ vs $28.8 \% ; P=.031)$, have a history of cancer $(1.7 \%$ vs $3.6 \% ; P=.007)$, or display clinical signs of infection $(37.4 \%$ vs $42.9 \% ; P=.016)$. There were $84(16.9 \%)$ diabetic donors whose hearts were transplanted into diabetic recipients.

\section{Posttransplant Outcomes}

Posttransplant outcomes are shown in Table 3. When outcomes in recipients of selected diabetic donors were compared with outcomes in recipients who received organs from nondiabetic donors, there was no difference in number of acute rejection episodes during initial hospitalization, length of stay, and need for retransplantation.

\section{Mortality}

Kaplan-Meier survival curves comparing recipients of hearts from diabetic donors with the control group are shown in Figure 1, A. There was no significant difference in 1-year (84.2\% vs $87.0 \%)$ and 3-year survival $(73.1 \%$ vs $70.1 \% ; P=.172)$. On univariate analysis, use of diabetic donor hearts was not associated with increased mortality (hazard ratio [HR]; 1.126, 95\% confidence interval [CI], $0.949-1.336 ; P=.172$ ). The results of Cox proportional regression analysis are shown in Table 4. On Cox proportional regression analysis, receiving a diabetic donor heart (HR, $1.155 ; 95 \%$ CI, $0.943-1.415 ; P=.164$ ) was not independently associated with mortality. As previously described, variables associated with mortality included increasing donor age (HR, 1.012 per year; 95\% CI, 1.010-1.015; $P<.001$ ), longer ischemic time (HR, 1.096 per hour; 95\% CI, 1.065-1.128; $P<.001$ ), recipient creatinine (HR, $1.108 / \mathrm{mg} / \mathrm{dL} ; 95 \%$ CI, 1.082-1.134; $P<.001)$, recipient black race (HR, 1.343; 95\% CI, 1.231-1.465; $P<.001$ ), race mismatch (HR, 1.098; 95\% CI, 1.023-1.178; $P=.010$ ), and use of mechanical ventilation (HR, 2.266; 95\% CI, 1.954-2.628; $P<.001$ ), or ECMO (HR, 2.550; 95\% CI, 1.854-3.506; $P<.001)$ as a bridge to transplantation. Increasing donor BMI was associated with survival (HR, 0.989/kg/m² ; 95\% CI, 0.983-0.995; $P=.003$ ). In addition, there were no significant interactions between diabetic donor hearts and recipient age $(P=.986)$, recipient gender $(P=.991)$, donor age $(P=.525)$, donor gender $(P=.461)$, ischemic time $(0.302)$, or recipient diabetes $(P=.792)$. Median follow-up for the study group was 1189.5 days.

Of the 496 diabetic donors, $222(44.8 \%)$ had insulindependent diabetes. As shown in Figure $1, B$, there was no significant difference in survival when comparing recipients of insulin-dependent diabetic donor hearts to non-insulindependent diabetic donor hearts nor to the control group.

Of the 496 diabetic donors, 182 (36.7\%) had a history of diabetes mellitus for over 5 years. There was no difference in median survival when using donors with a history of diabetes mellitus for greater than 5 years when compared with those with diabetes mellitus for 5 years or less or with the control group (Figure 1,C). On Cox proportional regression analysis of these subgroups, neither insulin-dependent diabetes (HR, 
TABLE 1. Baseline recipient characteristics

\begin{tabular}{|c|c|c|c|c|c|}
\hline & No. available & Nondiabetic donor $(n=19,852)$ & No. available & Diabetic donor $(n=496)$ & $P$ value \\
\hline Age (y) & 19,852 & $51.8 \pm 12.4$ & 496 & $53.4 \pm 11.8$ & .004 \\
\hline Male gender & 19,852 & $15,100(76.1)$ & 496 & $387(78.0)$ & .312 \\
\hline White & 19,852 & $14,459(72.8)$ & 496 & $366(73.8)$ & .697 \\
\hline Black & 19,852 & $3,286(16.6)$ & 496 & 89 (17.9) & - \\
\hline Hispanic & 19,852 & $829(4.2)$ & 496 & $16(3.2)$ & - \\
\hline Asian & 19,852 & $475(2.4)$ & 496 & $8(1.6)$ & - \\
\hline American Indian/Alaskan & 19,852 & $64(0.3)$ & 496 & $0(0.0)$ & - \\
\hline Hawaiian/Pacific Islander & 19,852 & $51(0.3)$ & 496 & $1(0.2)$ & - \\
\hline Multiracial & 19,852 & $686(3.5)$ & 496 & $16(3.2)$ & - \\
\hline Recipient BMI & 19,176 & $26.9 \pm 21.9$ & 483 & $27.2 \pm 5.1$ & .798 \\
\hline Recipient diabetes & & $2,633(14.9)$ & & $84(18.9)$ & .024 \\
\hline Mean ischemic time $(\mathrm{h})$ & 18,627 & $3.2 \pm 1.0$ & 469 & $3.3 \pm 1.1$ & .191 \\
\hline Cardiac output (L/min) & 17,773 & $4.3 \pm 1.4$ & 442 & $4.2 \pm 1.3$ & .255 \\
\hline Mean PVR (Wood units) & 15,304 & $2.37 \pm 2.0$ & 394 & $2.5 \pm 2.4$ & .191 \\
\hline Sex mismatch & 19,852 & $5,500(27.7)$ & 496 & $163(32.9)$ & .011 \\
\hline Race mismatch & 19,852 & $8,551(43.1)$ & 496 & $220(44.4)$ & .569 \\
\hline No. of HLA mismatches & 16,880 & $4.6 \pm 1.1$ & 430 & $4.7 \pm 1.1$ & .483 \\
\hline Creatinine before transplant $(\mathrm{mg} / \mathrm{dL})$ & 19,448 & $1.4 \pm 0.9$ & 486 & $1.4 \pm 0.7$ & .882 \\
\hline Creatinine clearance $(\mathrm{mL} / \mathrm{min})$ & 19,230 & $82.0 \pm 38.6$ & 480 & $80.8 \pm 32.3$ & .438 \\
\hline Mechanical ventilation before transplant & 19,852 & $553(2.8)$ & 496 & $24(4.8)$ & .007 \\
\hline ECMO before transplant & 19,852 & $103(0.5)$ & 496 & $4(0.8)$ & .382 \\
\hline
\end{tabular}

$B M I$, Body mass index; $P V R$, pulmonary vascular resistance; $H L A$, human leukocyte antigen; $E C M O$, extracorporeal membrane oxygenation.

$1.173 ; 95 \% \mathrm{CI}, 0.884-1.444 ; P=.268)$ nor duration of diabetes over 5 years (HR, $1.239 ; 95 \% \mathrm{CI}, 0.914-1.016 ; P=.167)$ was associated with mortality after cardiac transplantation.

We wished to test the hypothesis that outcome was superior in patients who received a heart from a diabetic donor who had undergone coronary angiography. Therefore, subgroup analysis was carried out on the $238(48.2 \%)$ of diabetic donors that were evaluated with coronary angiography. Cox proportional regression analysis of this subgroup showed no association with mortality (HR,
$1.191 ; 95 \%$ CI, 0.891-1.591; $P=.238)$. Similarly, use of diabetic donor hearts that were not evaluated with coronary angiography was not associated with mortality (HR, $1.129 ; 95 \%$ CI, 0.851-1.498; $P=.400)$.

\section{CONCLUSIONS}

Heart transplantation remains the gold standard for endstage heart failure. ${ }^{1,15,16}$ Increased efforts in expanding the donor pool have led to the use of donor hearts once thought to be unsafe for transplantation. ${ }^{2-8}$ This has

TABLE 2. Donor characteristics

\begin{tabular}{|c|c|c|c|c|c|}
\hline & No. available & $\begin{array}{l}\text { Nondiabetic donor } \\
\quad(n=19,852)\end{array}$ & No. available & $\begin{array}{l}\text { Diabetic donor } \\
\quad(n=496)\end{array}$ & $P$ value \\
\hline Donor age (y) & 19,852 & $31.3 \pm 12.3$ & 496 & $39.6 \pm 11.5$ & $<.001$ \\
\hline Donor Male & 19,852 & $14,226(71.7)$ & 496 & $290(58.5)$ & $<.001$ \\
\hline Donor BMI & 19,852 & $26.4 \pm 5.5$ & 496 & $29.9 \pm 6.7$ & $<.001$ \\
\hline Donor heavy cigarette use & 19,740 & $4,832(24.5)$ & 459 & $141(28.8)$ & .031 \\
\hline Ejection fraction $(\%)$ & 19,151 & $61.6 \pm 7.9$ & 480 & $61.7 \pm 7.2$ & .655 \\
\hline Serum creatinine (mg/dL) & 19,824 & $1.2 \pm 1.1$ & 496 & $1.5 \pm 1.5$ & $<.001$ \\
\hline Creatinine clearance $(\mathrm{mL} / \mathrm{min})$ & 19,824 & $120 \pm 56.1$ & 496 & $114.6 \pm 61.2$ & .053 \\
\hline Evaluation with echocardiogram & 19,138 & $18,664(97.5)$ & 481 & $453(94.2)$ & $<.001$ \\
\hline Evaluation with coronary angiography & 19,658 & $4,028(20.5)$ & 494 & $238(48.2)$ & $<.001$ \\
\hline Requirement of inotropic support at procurement & 14,062 & $7,967(56.7)$ & 392 & $237(60.5)$ & .134 \\
\hline Requirement of antihypertensives before crossclamp & 19,783 & 3,901 (19.7) & 494 & $94(19.0)$ & .703 \\
\hline Requirement of vasodilator before crossclamp & 19,788 & $2,522(12.8)$ & 496 & $67(13.5)$ & .615 \\
\hline History of myocardial infarction & 19,784 & $197(1.0)$ & 491 & $8(1.6)$ & .166 \\
\hline Donor history of cancer & 19,844 & $338(1.7)$ & 495 & $18(3.6)$ & .007 \\
\hline Donor cocaine use & 19,492 & $2,572(13.0)$ & 491 & $71(14.3)$ & .309 \\
\hline Donor history of infection & 18,877 & $7,051(37.4)$ & 478 & $205(42.9)$ & .016 \\
\hline
\end{tabular}

$B M I$, Body mass index. 
TABLE 3. Postoperative outcomes

\begin{tabular}{|c|c|c|c|c|c|}
\hline & No. available & Nondiabetic donor $(n=19,852)$ & No. available & Diabetic donor $(n=496)$ & $P$ value \\
\hline Acute rejection episode before discharge & 12,139 & $1,821(15.0)$ & 358 & $52(14.5)$ & .863 \\
\hline Deaths & 19,850 & $5,212(26.3)$ & 496 & $130(26.2)$ & .926 \\
\hline Retransplant & 19,850 & $216(1.1)$ & 496 & $5(1.0)$ & .926 \\
\hline Length of stay (d) & 19,620 & $20.1 \pm 25.0$ & 488 & $21.2 \pm 21.9$ & .339 \\
\hline
\end{tabular}

resulted in use of older donors ${ }^{17-19}$ and organs with longer ischemic time. ${ }^{20,21}$ In this study, we attempt to determine whether carefully selected hearts from donors with diabetes could be used with acceptable outcomes. We hypothesized that the use of carefully accepted donor hearts from persons with diabetes is safe, even in donors who are dependent on insulin or have had diabetes for more than 5 years.

Existing studies on the associations between donor diabetes and outcomes after heart transplantation are conflicting. ${ }^{8,14}$ Smits and associates ${ }^{14}$ designed and validated a donor scoring system for heart transplantation using the Eurotransplant Registry. In this study, donor diabetes was not associated with increased recipient mortality. However, this study consisted of only 41 diabetic donors, which did not allow for meaningful subgroup analysis. Stehlik and colleagues ${ }^{8}$ analyzed the Cardiac Transplant Research Database, also finding no overall relationship between donor diabetes and outcomes. The authors did, however, note that in a subgroup of male donors $(n=85)$, worse outcomes were associated with diabetes. We were unable to demonstrate this interaction between donor gender and diabetes, as Stehlik and coworkers ${ }^{8}$ did, nor were we able to demonstrate significant interactions between diabetic donors and donor age, recipient gender, recipient age, or ischemic time. There were 84 diabetic donor hearts that were transplanted into diabetic recipients. There was not a significant interaction between diabetic donor hearts and diabetic recipients, indicating that outcomes are no different when both donor and recipient are diabetic. As such, these findings from a large national database indicate that the use of carefully selected donor hearts that fulfill standard criteria for transplantation but also are affected by diabetes does not appear to be associated with increased recipient mortality. Given that these findings were consistent across a wide range of subgroup analyses, it is therefore likely that carefully selected hearts from donors with diabetes can be used for transplantation with acceptable outcomes.

On subgroup analysis, neither insulin dependence nor duration of diabetes was associated with increased mortality. A power analysis demonstrated that there were sufficient numbers of insulin-dependent donors. A 2-sided log-rank test with an overall sample size of 20,346 subjects $(19,850$ in the control group and 496 in the experimental group) achieved $91.7 \%$ power at a .05 significance level to detect a hazard ratio of 1.173 as seen in the subjects with insulin-dependent diabetes. For duration of diabetes, the same analysis achieved $99.0 \%$ power at a .05 significance level to detect a hazard ratio of 1.239 as seen in donors with duration of diabetes for over 5 years. The UNOS database does not have information regarding donor insulin requirement. Further studies are needed to determine whether degree of donor insulin dependence is associated with recipient survival. In addition, data on donor blood sugar control, severity of diabetes, or presence of end-organ damage secondary to diabetes was not available. Further research is needed to determine how these markers may affect recipient survival. This in turn may shed additional light on how to

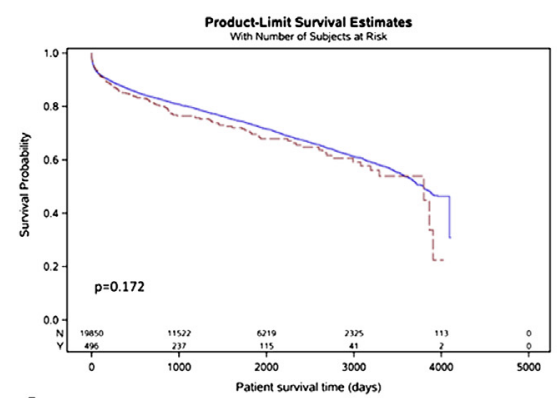

A

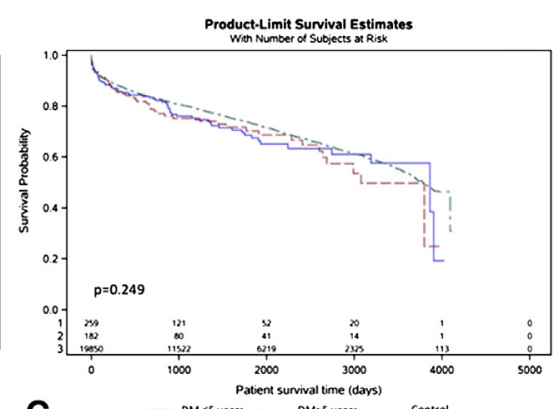

C —om ss years .... DMas years .... contro

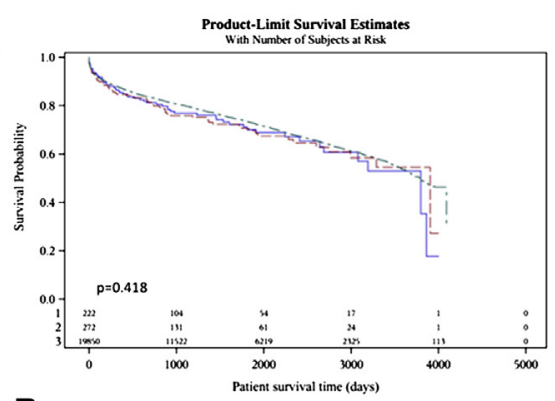

- $100 \mathrm{M}$.... NiDOM -... control

FIGURE 1. A, Kaplan-Meier survival curves comparing recipients of nondiabetic donor hearts $(N)$ with patients receiving diabetic donor hearts $(Y)$. B, Comparison of recipients of insulin-dependent (1) and non-insulin-dependent diabetic donor hearts (2) with patients receiving nondiabetic donor hearts (3). C, Comparison of recipients of donor hearts with a history of diabetes of 5 years or less (1) and more than 5 years (2) with patients receiving nondiabetic donor hearts (3). IDDM, Insulin-dependent diabetes mellitus; NIDDM, non-insulin-dependent diabetes mellitus; DM, diabetes mellitus. 
TABLE 4. Multiple variable model predicting risk of mortality overall

\begin{tabular}{lccr}
\hline & $\begin{array}{c}\text { Hazard } \\
\text { ratio }\end{array}$ & $\begin{array}{c}\mathbf{9 5} \% \text { Confidence } \\
\text { interval }\end{array}$ & $\begin{array}{c}\boldsymbol{P} \\
\text { value }\end{array}$ \\
\hline Diabetic donor & 1.155 & $0.943-1.415$ & .164 \\
Donor age (per y) & 1.012 & $1.010-1.015$ & $<.001$ \\
Donor BMI (per kg/m ${ }^{2}$ ) & 0.989 & $0.983-0.995$ & .003 \\
Donor female gender & 0.943 & $0.875-1.017$ & .128 \\
Ischemic time (per h) & 1.096 & $1.065-1.128$ & $<.001$ \\
Recipient creatinine (per mg/dL) & 1.108 & $1.082-1.134$ & $<.001$ \\
Recipient female gender & 0.967 & $0.897-1.042$ & .390 \\
Recipient age (per y) & 0.999 & $0.996-1.002$ & .423 \\
Recipient history of diabetes & 1.064 & $0.966-1.172$ & .211 \\
White race & Ref & Ref & Ref \\
Asian race & 0.817 & $0.645-1.034$ & .093 \\
Black race & 1.343 & $1.231-1.465$ & $<.001$ \\
Hispanic race & 1.048 & $0.924-1.188$ & .466 \\
Sex mismatch & 1.059 & $0.985-1.139$ & .136 \\
Race mismatch & 1.098 & $1.023-1.178$ & .010 \\
ECMO as bridge to transplant & 2.550 & $1.854-3.506$ & $<.001$ \\
Ventilator as bridge to transplant & 2.266 & $1.954-2.628$ & $<.001$ \\
\hline
\end{tabular}

$B M I$, Body mass index; ECMO, extracorporeal membrane oxygenation.

manipulate the neurohormonal brain-death milieu to maximize donor conversion. We also carried out subgroup analysis on diabetic donor hearts that were evaluated with coronary angiography. Recipients of diabetic donors that had coronary angiography did not have superior outcomes.

Recipient variables found to be associated with mortality in this study were creatinine, black race, and requirement of mechanical ventilation as a bridge to transplantation. These variables are consistent in what has been established in previous studies. $^{9-13,22}$ The requirement of ECMO as a bridge to transplantation was found to be strongly associated with death. Other factors associated with mortality in this study included race mismatch, longer ischemic time, and increasing donor age. These variables have been shown to be associated with mortality in prior studies. ${ }^{9-13,23,24}$

There were several limitations to this study, including those related to its retrospective nature. There are inherent limitations in using a multi-institutional database such as UNOS. Although we cannot confirm that the data are devoid of coding errors, any such errors are likely random and unlikely to create bias. In addition, UNOS does not include all potential confounders, such as detailed socioeconomic data. There are some donor characteristics that may confound the results of the study and could not be evaluated in the UNOS database, such as severity of nephropathy and presence of myocardial infarctions. Future studies are needed to determine whether these variables affect outcomes when using diabetic donors. Finally, median follow-up for this study was 1189.5 days and the use of diabetic donors may have long-term effects that could not be observed in this study period.

In conclusion, this study demonstrates that cardiac transplantation can be safely performed using carefully selected diabetic donors. Such donors can be used for transplantation with equivalent outcomes, even when the donor is insulin dependent or has had diabetes for more than 5 years.

\section{References}

1. Taylor DO, Edwards LB, Boucek MM, Trulock EP, Aurora P, Christie J, et al. Registry of the International Society for Heart and Lung Transplantation: twenty-fourth official adult heart transplant report-2007. J Heart Lung Transplant. 2007;26:769-81.

2. Chen JM, Sinha P, Rajasinghe HA, Suratwala SJ, McCue JD, McCarty MJ, et al. Do donor characteristics really matter? Short- and long-term impact of donor characteristics on recipient survival, 1995-1999. J Heart Lung Transplant. 2002;21:608-10.

3. Izquierdo M, Almenar L, Martinez-Dolz L, Moro J, Aguero J, SanchezLazaro O, et al. Analysis of the impact of donor gender on early mortality. Transplant Proc. 2007;2375-6.

4. Laks H, Marelli D, Fonarow GC, Hamilton MA, Ardehali A, Moriguchi JD, et al. Use of two recipient lists for adults requiring heart transplantation. J Thorac Cardiovasc Surg. 2003;125:49-59.

5. Lima B, Rajagopal K, Petersen RP, Shah AS, Soule B, Felker GM, et al. Marginal cardiac allografts do not have increased primary graft dysfunction in alternate list transplantation. Circulation. 2006;114(1 Suppl):I27-32.

6. Marelli D, Bresson J, Laks H, Kubak B, Fonarow G, Tsa F, et al. Hepatitis C-positive donors in heart transplantation. Am J Transplant. 2002;2:443-7.

7. Ott GY, Herschberger RE, Ratkovec RR, Norman D, Hosenpud JD, Cobanoglu A. Cardiac allografts from high-risk donors: excellent clinical results. Ann Thorac Surg. 1994;57:76-82.

8. Stehlik J, Feldman DS, Brown RN, Van Bakel AB, Russel SD, Ewald GA, et al. Interactions among donor characteristics influence post-transplant survival: a multi-institutional analysis. J Heart Lung Transplant. 2010;29:291-8.

9. Kilic A, Weiss ES, George TJ, Arnaoutakis GJ, Yuh DD, Shah AS, et al. What predicts long-term survival after heart transplantation? An analysis of 9,400 ten-year survivors. Ann Thorac Surg. 2012;93:699-704.

10. Kilic A, Weiss ES, Yuh DD, Shah AS, Conte JV. Factors associated with 5-year survival in older heart transplant recipients. J Thorac Cardiovasc Surg. 2012;143: 468-74.

11. Segovia J, Cossio MDG, Barcelo JM, Bueno MG, Pavia PG, Burgos R, et al. RADIAL: a novel primary graft failure risk score in heart transplantation. $J$ Heart Lung Transplant. 2011;30:644-51.

12. Weiss ES, Allen JG, Arnaoutakis GJ, George TJ, Russell SD, Shah AS, et al. Creation of a quantitative recipient risk Index for Mortality Prediction After Cardiac Transplantation (IMPACT). Ann Thorac Surg. 2011;92:914-22.

13. Weiss ES, Allen JG, Kilic A, Russell SD, Baumgartner WA, Conte JV, et al. Development of a quantitative donor risk index to predict short-term mortality in orthotopic heart transplantation. J Heart Lung Transplant. 2012;31: 266-73.

14. Smits JM, De Pauw M, de Vries E, Rahmel A, Meiser B, Laufer G, et al. Donor scoring system for heart transplantation and the impact on patient survival. J Heart Lung Transplant. 2011;31:387-97.

15. Tsao C, Chen R, Chou N, Chou NK, Ko WJ, Chi NG, et al. The influence of donor characteristics on survival after heart transplantation. Transplant Proc. 2008;2636-7.

16. Levy D, Kenchaiah S, Larson MG, Benjamin EJ, Kupka MF, Ho KKL, et al. Long-term trends in the incidence of and survival with heart failure. $N$ Engl J Med. 2002;347:1397-402.

17. Blanche C, Kamlot A, Blanche D, Kearney B, Magliato K, Czer L, et al. Heart transplantation with donors fifty years of age and older. $J$ Thorac Cardiovasc Surg. 2002; 123:810-5.

18. Loebe M, Potapov EV, Hummel M, Weng Y, Bocksch W, Hetzer R. Mediumterm results of heart transplantation using older donor organs. J Heart Lung Transplant. 2000;19:957-63.

19. Tenderich G, Koerner MM, Stuettgen B, Arusoglu L, Bairaktaris A, Hornik L, et al. Extended donor criteria: hemodynamic follow-up of heart transplant recipients receiving a cardiac allograft from donors $>$ or $=60$ years of age. Transplantation. 1998;66:1109-13.

20. Mitropoulos FA, Odim J, Marelli D, Marelli D, Karandikar K, Gjertson D, et al. Outcome of hearts with cold ischemic time greater than 300 minutes. A casematched study. Eur J Cardiothorac Surg. 2005;28:143-8. 
21. Morgan JA, John R, Weinberg AD, Kherani AR, Colletti NJ, Vigilance DW, et al. Prolonged donor ischemic time does not adversely affect long-term survival in adult patients undergoing cardiac transplantation. J Thorac Cardiovasc Surg. 2003;126:1624-33.

22. Allen JG, Weiss ES, Arnaoutakis GJ, Russell SD, Baumgartner WA, Conte JV, et al. The impact of race on survival after heart transplantation: an analysis of more than 20,000 patients. Ann Thorac Surg. 2010;89:1956-64.
23. Patel ND, Weiss ES, Nwakanma LU, Russel SD, Baumgartner WA, Shah AS, et al. Impact of donor-to-recipient weight ratio on survival after heart transplantation: analysis of the United Network for Organ Sharing Database. Circulation. 2008;118:S83-8

24. Bove AA, Kashem A, Cross RC, Wald J, Furukawa S, Bergman GO, et al. Factors affecting survival after heart transplantation: comparison of pre-and post-1999 listing protocols. J Heart Lung Transplant. 2006;25:42-7. 